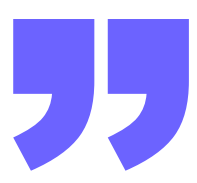

\title{
THE ANALYSIS OF PHRASAL VERBS FOUND IN BLOOD DIAMOND MOVIE BY EDWARD ZWICK
}

\author{
Muhammad Reza Jufri Yasin'1, I Gusti Bagus Wahyu Nugraha²,I Gusti \\ Agung Sri Rwa Jayantini ${ }^{3}$ \\ Mahasaraswati Denpasar University, Indonesia ${ }^{123}$ \\ ejaa9446@gmail.com
}

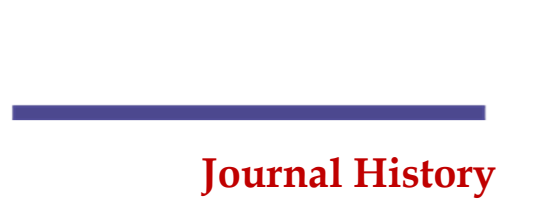

Submitted 15 th Februari 2021

Revised 29th March 2021

Accepted 25 th April 2021

Published 29th July 2021

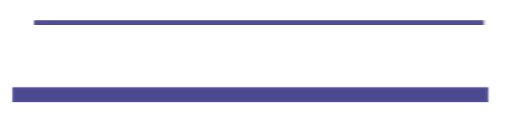

Keywords:

Phrasal Verbs, Movie Literature, Descriptive Qualitative

\begin{abstract}
This study investigated the types of phrasal verbs encountered in a movie entitled Blood Diamond. The problems of this study is what types of phrasal verb are found in the movie entitled Blood Diamond?. This study employed descriptive and qualitative method to provide a well-organized description regarding the problems being identified. The data of this study were obtained by observation method through four stages. Firstly, watching the Blood Diamond movie. Secondly, finding and taking notes the phrasal verb spoken by the characters in the movie Blood Diamond. Reading the online movie script and finally the writer categorized the types of data based on the theory proposed by McCarthy E O'Dell (2007:8). There were two types of phrasal verb encountered namely transitive and intransitive phrasal verb, in which transitive phrasal verb can be specialized into separable or non-separable transitive phrasal verb. The result of the study demonstrated that there are 8 data of phrasal verbs discovered in the movie Blood Diamond consisting 4 transitive phrasal verbs and 4 intransitive phrasal verbs.
\end{abstract}

\section{INTRODUCTION}

Phrasal verbs are the core part of English vocabulary, it is additionally a fundamental part of English history, heritage and culture. In English verbal communication, phrasal verb holds considerable role for the original English speaker to conversate in informal situation or everyday dialogue. English EFL/ESL students and learners in general have difficulties in comprehending the meaning of phrasal verbs especially when having conversation in English and tend to be unable to communicate using phrasal verbs correctly (Thyab, 2019). McCarthy \& O'Dell (2007:6) states 
that phrasal verbs are general to find in various contexts. We may have noticed in a song by The Beatles sounds I'll get by with a little help from my friends, furthermore a song by Bob Marley sounds Get up, stand up and Red Hot Chili Peppers Knock me down. Phrasal verbs are identical in informal type of English, however they can also be spoken or written in more formal English.

The use of phrasal verbs in this modern era can be found in many literary works, such as novels, song lyrics, articles, magazines, newspapers and movies. From those many literary works, the writer selected movie to analyze the use of phrasal verb in form of utterance spoken by the characters throughout the movie selected. In this research, the writer conducted an analysis of English phrasal verb found in a movie entitled Blood Diamond. There is one problem in this research to reveal namely (1) What types of phrasal verb found in Blood Diamond movie?. This research was conducted to reveal about the types of phrasal verb found in a movie entitled Blood Diamond. This movie is spoken in English and it has been translated into Indonesian as the subtitle by Sukair, Banda Aceh, 11th October 2010. Furthermore, the writer's reason for selecting phrasal verb to be analyzed is because phrasal verb is easily found in literary works such as movie, music, novel and many more. Hence, this work became an interesting object. The writer selected this movie since it was raised based on the true story taking place in South Africa and it additionally provides a great deal of phrasal verbs in form of utterance. Furthermore, this movie had been awarded as one of the best movies nominated by National Award and also played by the best main character in 2007. In spite of phrasal verbs belong to informal type of language, yet its existence clearly takes place in English speaking countries. One obvious example of phrasal verb is give back, when you return something to someone you give it back (Hart, 1999:2). This sentence is a phrasal verb due to the verb give is followed with a preposition back.

This research has a thing in common with another research conducted by Ahayu (2018) entitled Analysis Kinds of Phrasal Verbs in the Ted Talk Speech "The Power of Introverts" Produced by Susan Cain in Edition on March 2018 in which both studies investigated the types of phrasal verb. Their research focused on describing the kinds of phrasal verbs used in the formal communication in TED talk speech The Power of Introverts produced by Susan Cain in edition on March, 2012 and discovering the dominants of phrasal verbs in the formal communication in TED talk speech The Power of Introverts produced by Susan Cain in edition on March, 2012. In conducting their research, descriptive qualitative method was applied. The result of their research demonstrated that there are 41 phrasal verbs and 17 separable phrasal verbs. The difference between 
both studies was on the data source in which this study applied movie as the data source meanwhile their study adopted speech as the data source.

Another research conducted by Manik, Sudarsono \& Rosnija (2013) entitled An Analysis of Phrasal Verbs in Movie "Pride and Prejudice". The both studies were alike analyzing the phrasal verbs in a movie. Nonetheless, there is also a difference occurred between both studies namely this research discussed the types of phrasal verb found, meanwhile their research did not. Their research focuses on analyzing the meanings of the phrasal verb found in the movie entitled Pride and Prejudice. Furthermore, in conducting their research, descriptive method was applied.

The next research was taken from Wulandari (2017) entitled An Analysis of English Phrasal Verb in Abandon Novel and Its Translation. Their study investigated the difficulties encountered by the researcher in the translation of English phrasal verb and to solve the difficulties faced by the researcher in translating English phrasal verb. The result of their research indicates that there are shifting of the phrasal verbs found in Abandon novel, they are level shift consists of phrasal verbs into verbs. Furthermore, structure shift that is phrasal verb into a verb. The proceeded denotes that translation shifts from phrasal verb into verb is dominant. The equivalence of the data is divided into two namely equivalent of translation and non-equivalent. And the equivalence covers formal and dynamic equivalence. The difference between this study and their study is on the data source in which that data of this study is entirely retrieved from a movie meanwhile the other one used novel entitled Abandon.

\section{METHODS}

The data of this study was completely retrieved from Blood Diamond movie directed by Edward Zwick released in 2006. The length of this movie is two hours and twenty three minutes. This movie is spoken in English and it tells a story about illegal diamond mines taking place in South Africa where the diamond mines are taken over by the rebels and the entire diamonds found are used to purchase arms and finance civil war as well as to fight against the government. This movie is raised from a true story that was taking place in South Africa in 2003 and casted by several Hollywood movie players such as Leonardo Di Caprio, Djimon Hounsou, Jennifer Connelly and Arnold Vosloo. The writer selected this movie since it was made based on the true story taking place in South Africa and it additionally provides a great deal of phrasal verbs in form of utterance. Furthermore, this movie had been awarded as one of the best movies nominated by National Award and also played by the best main character in 2007. 
This research employed observation method which is by conducting direct research, as for the steps of collecting the data are as follow (1) Watch Blood Diamond movie, the first step in collecting the data is the writer watched the movie entitled Blood Diamond. (2) Find and take note the data of phrasal verb in Blood Diamond movie, the next step is the writer seeked the data of phrasal verb spoken by the characters in Blood Diamond movie. After finding the data, the writer took note of each data found. (3) Read the movie script, the third step is the writer read the online movie script to ensure the data are valid. (4) Categorize the types of data, and finally the writer categorized the types of each data found based on the theory by McCarthy \& O’Dell (2007:8).

After the data have been entirely obtained, the next step is analyzing the data. The analysis is conducted using descriptive qualitative method to create description systematically as well as the relationship with the object being investigated. The findings are discussed by identifying and categorizing the types of phrasal verbs based on the theory McCarthy and O'dell (2007) supported by Hart (1999).

Furthermore, the data found are presented both formal and informal method. As for formal method is a method in analyzing the findings by using a table, however formal method is most likely to require assistance from informal method using descriptive sentence to discuss each data.

\section{RESULTS AND DISCUSSION}

\section{RESULT}

The result of the research is answering the problem of the study proposed earlier. In conducting the research, the writer encountered multiple phrasal verbs whose type belongs to transitive and intransitive phrasal verbs.

\begin{tabular}{l|lll}
\multicolumn{1}{l}{ No. } & Types of Phrasal Verb & Frequency & Percentage \\
\hline 1. & Transitive Phrasal Verb & 4 & $50 \%$ \\
\hline 2. & Intransitive Phrasal Verb & 4 & $50 \%$ \\
\hline \multicolumn{2}{l}{ Total } & 8 & $100 \%$
\end{tabular}

Table above demonstrates the types, frequency and percentage of phrasal verb found in the movie entitled Blood Diamond. It is found as many as 8 data of phrasal verbs that can be formulated into two types namely transitive phrasal verb and intransitive phrasal verb. The both types of phrasal verb are alike occurred as many as 4 times throughout the movie. It is formed by 4 intransitive phrasal verbs, 3 transitive non-separable phrasal verbs and 1 transitive separable phrasal verb. 


\section{DISCUSSION}

The writer presented the phrasal verb in a form of sentence as uttered by the character of the movie selected. The writer depended on the theory by McCarthy \& O'Dell (2007:8) to identify the types of phrasal verb. In addition, to be able to distinguish the transitive separable and transitive non-separable phrasal verb, the writer depended on the theory by Hart (1999:9).

\begin{tabular}{l|lll} 
No. & $\begin{array}{l}\text { Phrasal verb found in the } \\
\text { movie }\end{array}$ & Type & Minute \\
\hline 1. & Take away & Transitive & 00:14:36 \\
\hline 2. & Stay around & Intransitive & 00:25:37 \\
\hline 3. & Piss off & Intransitive & 00:26:55 \\
\hline 4. & Get away & Intransitive & 00:29:37 \\
\hline 5. & Buy up & Transitive & 00:38:19 \\
\hline 6. & Keep off & Transitive & 01:03:01 \\
\hline 7. & Shell out & Transitive & $01: 03: 19$ \\
\hline 8. & Going on & Intransitive & $01: 05: 31$
\end{tabular}

The table above indicates the phrasal verbs discovered in a movie entitled Blood Diamond additionally their type and the time of the phrasal verbs spoken consisting of hour, minute and second.

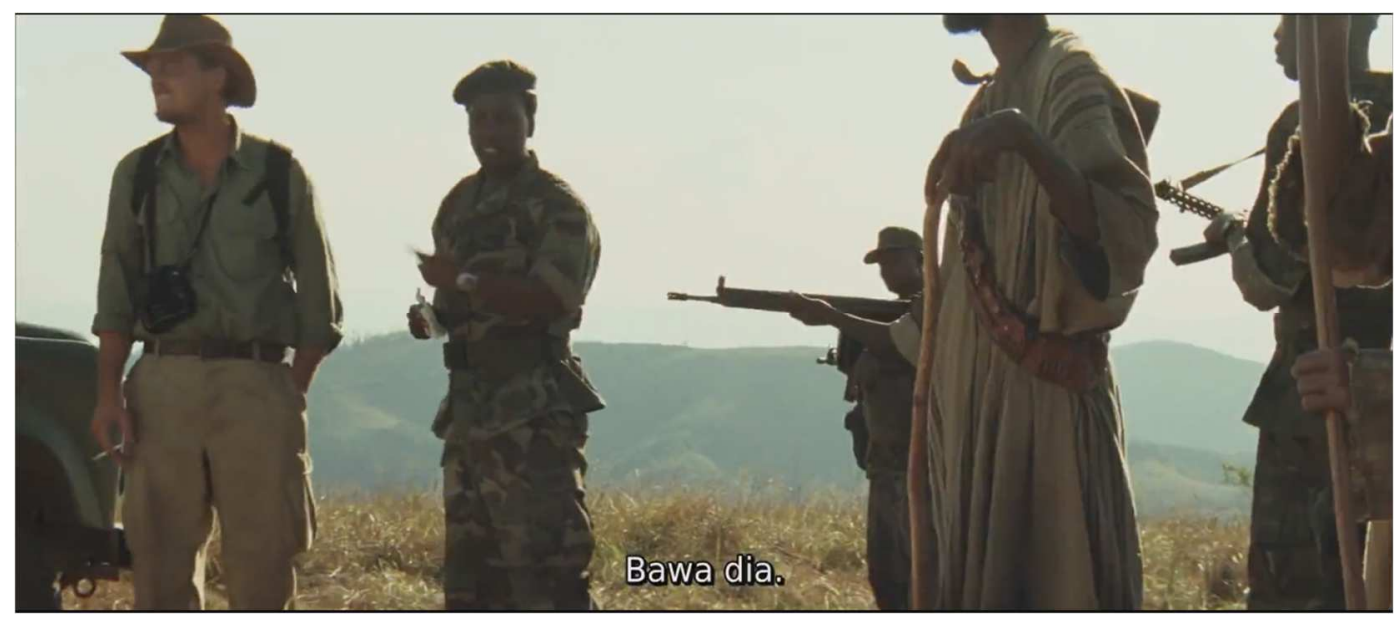

Soldier: "Guys, take him away"

The utterance spoken by the soldier above contains a phrasal verb namely take away. It is categorized as a phrasal verb since the verb take is followed with an adverb away. As stated in Woodward English (2000), take away is a phrasal verb to take someone or something when leaving a place. The phrasal verb above belongs to transitive separable phrasal verb since it takes an object him in which the object is placed between take and away. This utterance is performed by a soldier to his subordinates to bring someone along as he is arrested for smuggling illegal diamond across the border. 


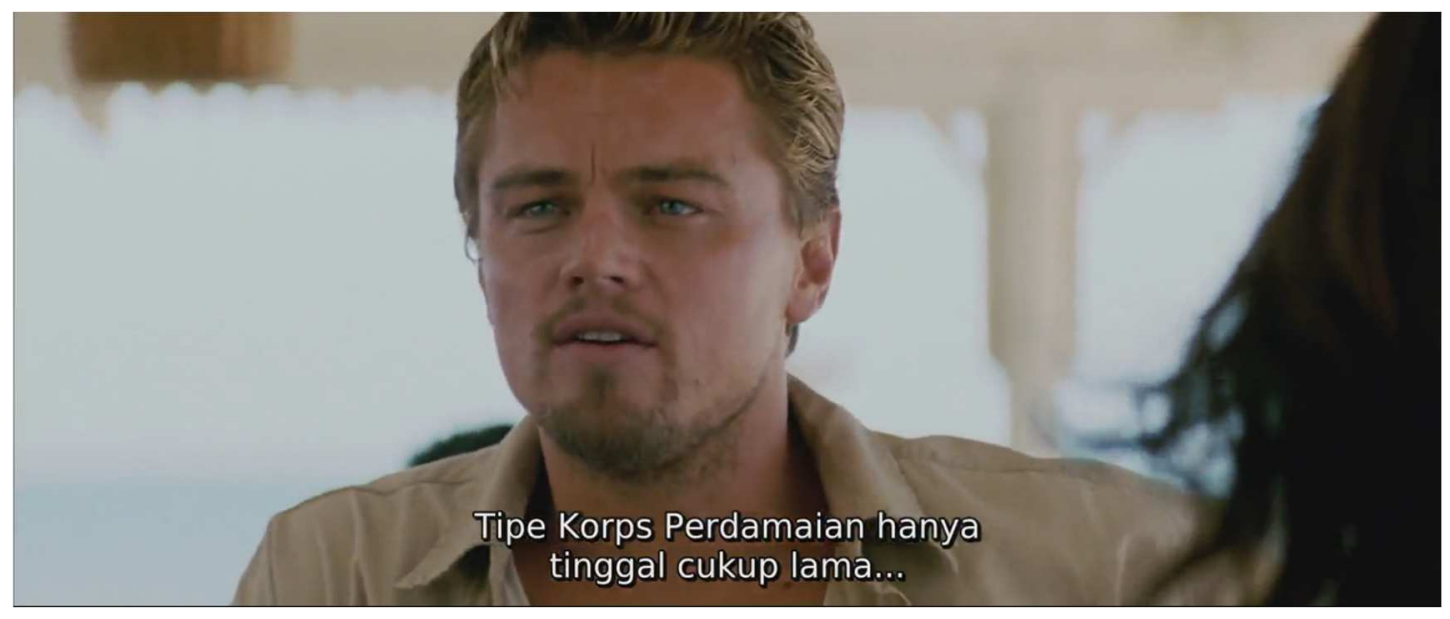

Danny Archer: "Peace corps types only stay around long enough....."

The sentence expressed by Danny Archer above consists of a phrasal verb namely stay around. According to Hornby (2000), stay around is a phrasal verb that refers to not leave somewhere. The phrasal verb stay around is formed with a verb stay and an adverb around. After that, the phrasal verb above is included in intransitive phrasal verb since it does not take any objects.

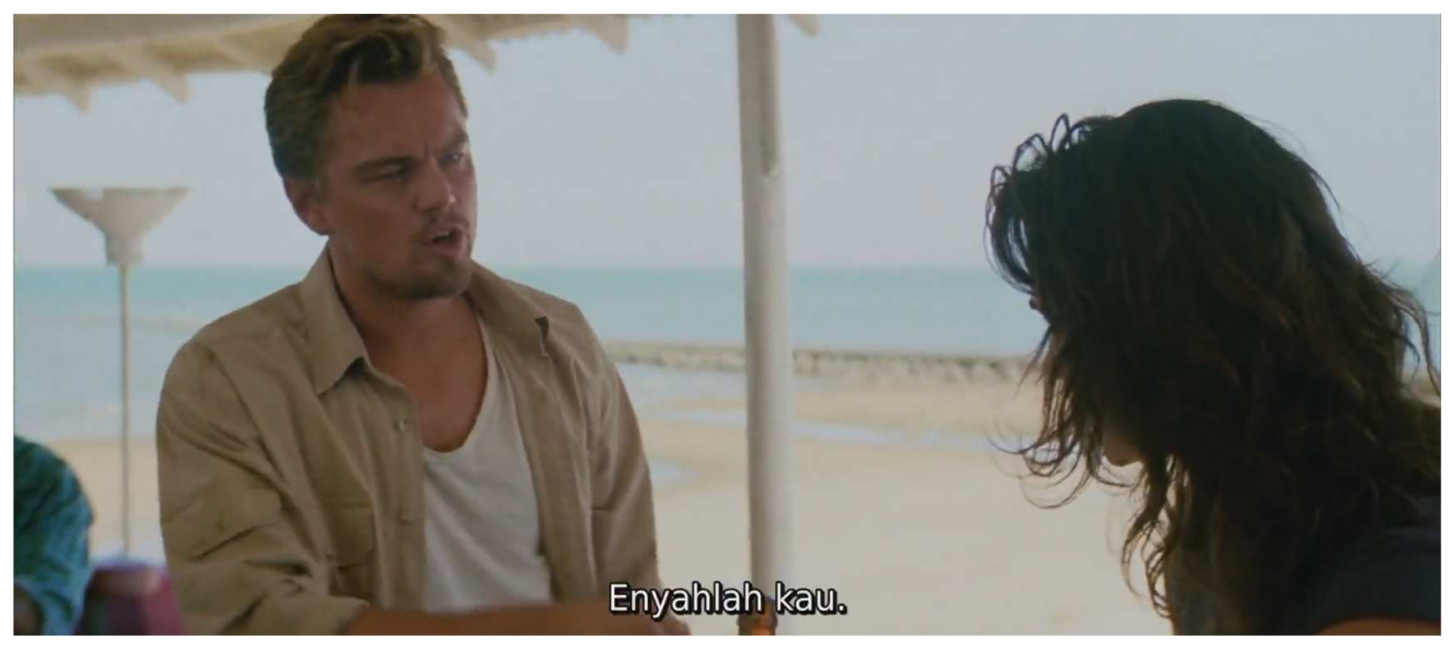

Danny Archer: "Piss off, huh"

In line with Hornby (2000), piss off is a slang or taboo word that is generally used in orders to someone to go away. It is formed with a verb piss an adverb off making them a phrasal verb. The phrasal verb piss off is categorized as intransitive phrasal verb since the object in the sentence does not exist. This phrasal verb is spoken by Danny Archer when he meets a new person which is also a journalist. 


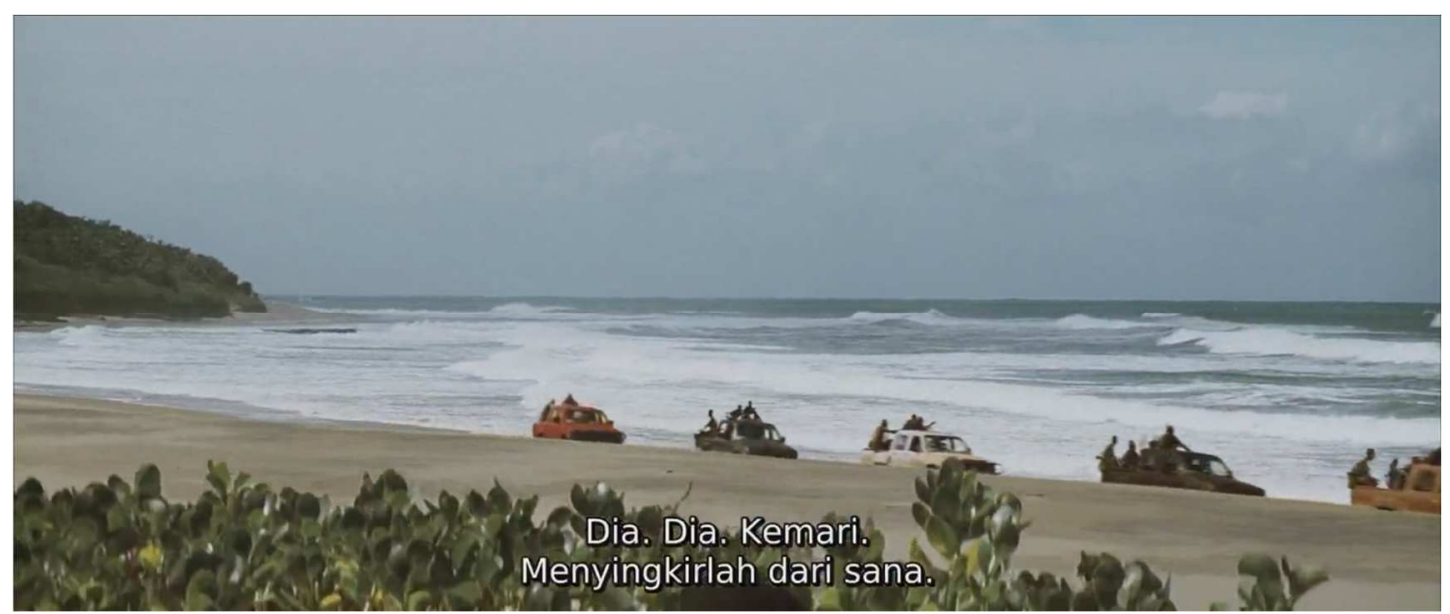

Another character: "Get away from there"

The statement spoken by another character above covers a phrasal verb that is get away. It is classified as a phrasal verb since the verb get is followed with an adverb away. Based on the form of the sentence, the phrasal verb above belongs to intransitive phrasal verb since there can not be found an object between nor after the phrasal verb. In Collins English Dictionary is stated that "when someone or something gets away, or when you get them away, they escape". This sentence is uttered by a mother to her son to get back since there is danger coming closer.

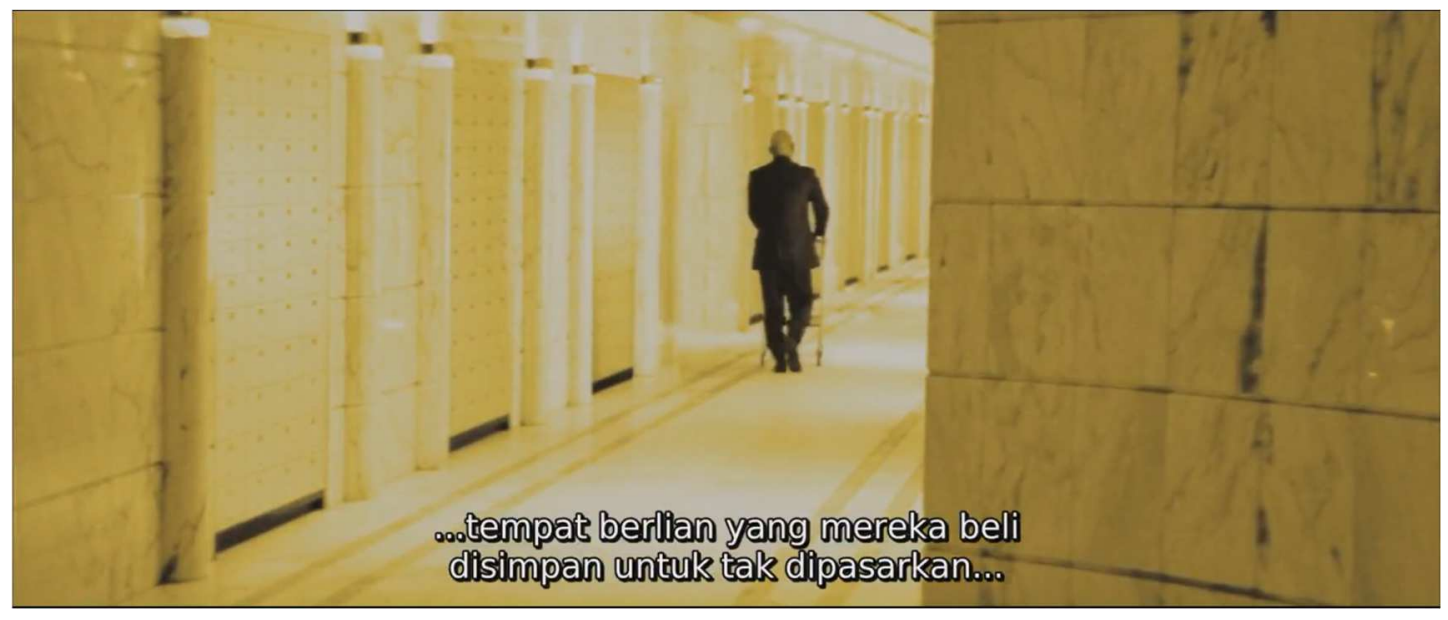

Danny Archer: "....where they put all the stones they buy up to keep off the market...."

According to the statement above, there can be found two phrasal verbs in one sentence namely buy up and keep off. Buy up is a phrasal verb since it can be seen that buy is a verb being accompanied with an adverb up afterwards. The phrasal verb buy up is classified into transitive nonseparable phrasal verb since the object does exist namely all the stones before the phrasal verb. As explained by Hornby (2000), buy up is a phrasal verb that is used to purchase all or any possible amount of particular thing. 
Next, there can also be found another phrasal verb in the sentence above namely keep off. As stated by Hornby (2000), keep off is a phrasal verb that is meant to avoid mentioning or publishing a particular subject. Judging by the sentence above, the phrasal verb keep off belongs to transitive non-separable phrasal verb since there can be found an object the market after the phrasal verb keep off.

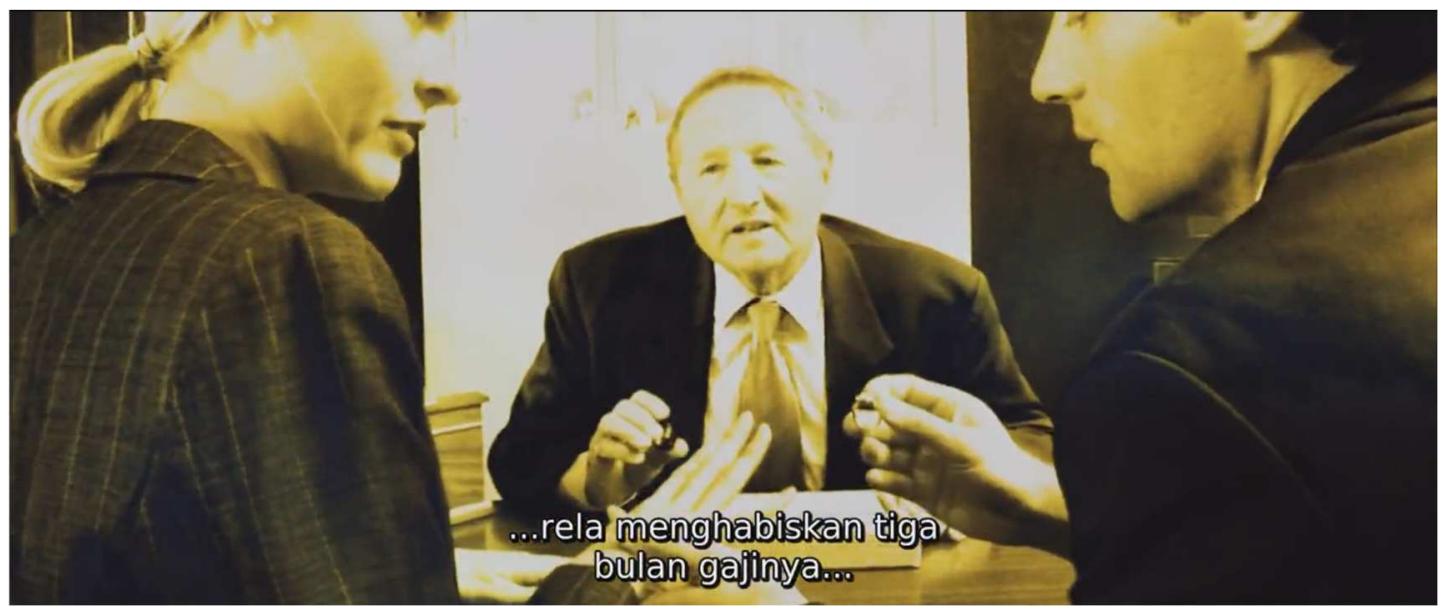

Danny Archer: “....He's supposed to shell out three months' salary....”

Based on the statement uttered by Danny Archer above, there can be found a phrasal verb namely shell out. It covers a verb shell and an adverb out making them as a phrasal verb. Hornby (2000) explains that shell out means paying for something with a huge amount of money. It can be seen from the sentence above, the phrasal verb is inferred as a transitive nonseparable phrasal verb since it is followed with an object three months' salary afterwards.

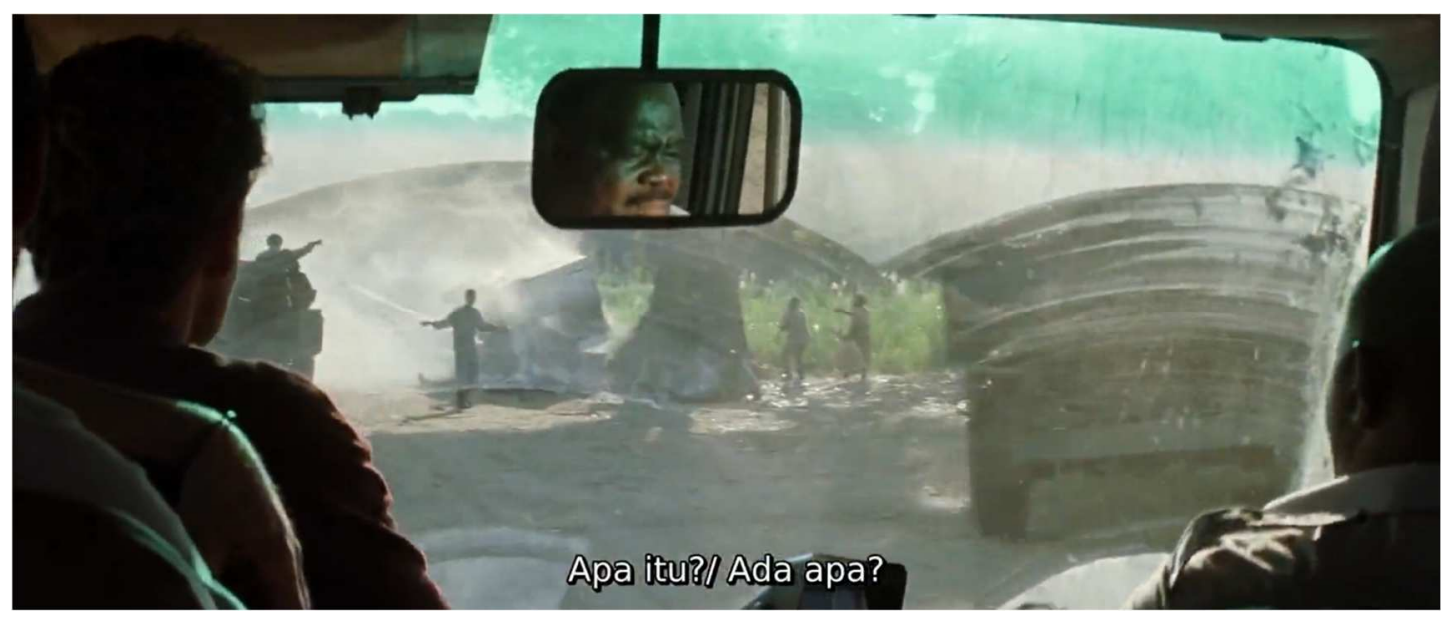

Another character: "What's going on?"

The another phrasal verb is going on. In the fragment of the movie above, there is one character uttering a phrasal verb in a sentence whose type is intransitive phrasal verb. It is categorized as a phrasal verb due to 
the verb go added suffix ing is accompanied with an adverb on. Hornby (2000) explains that be going on means to happen. In addition, the reason why it is included in intransitive phrasal verb is the object in the sentence does not exist. The phrasal verb is performed by the character in a bus encounters burned vehicle ahead.

\section{CONCLUSION}

In accordance to the results of the data analysis of the phrasal verbs used in the movie entitled Blood Diamond, there are multiple phrasal verbs whose type consist of transitive and intransitive phrasal verb, in which the transitive phrasal verb can be specified into separable and non-separable transitive phrasal verb. The total amount of phrasal verbs found in Blood Diamond movie is 8 consisting of 4 transitive phrasal verbs and the other 4 are intransitive phrasal verbs. In addition, there is 1 separable phrasal verb and 3 non-separable phrasal verbs found in Blood Diamond movie. The phrasal verbs found are mostly spoken by Danny Archer due to they play as the main character in the Blood Diamond movie.

\section{REFERENCES}

Ahayu (2018) Analysis Kinds of Phrasal Verbs in the Ted Talk Speech “The Power of Introverts" Produced by Susan Cain in Edition On March 2018. Thesis

Blood Diamond. Directed by Edward Zwick

Blood Diamond (n.d.). Scripts.com. Retrieved June 6, 2021, from https://www.scripts.com/script/blood_diamond_4290.

Hart, (1999) The Ultimate Phrasal Verbs Book

Hornby, (2000) Oxford Advanced Learner's Dictionary

Thyab, R. H. (2019) Phrasal Verbs in English as a Second/Foreign Language. Article

McCarthy, M. \& O’Dell, F., (2007) English Phrasal Verbs in Use

Manik, L.P., Sudarsono and Rosnija, (2013) An analysis of Phrasal Verbs in Movie "Pride and Prejudice". Thesis, Tanjungpura University

Wulandari, (2005) An Analysis of English Phrasal Verb in Abandon Novel and Its Translation. Article, Gunadarma University 